\title{
Effects of controlled hypotension with restrictive transfusion on intraoperative blood loss and systemic oxygen metabolism in elderly patients who underwent lumbar fusion
}

Xiaodong Qiu ${ }^{1 *}$, Zhiying Tan ${ }^{1}$, Wenhao Tang ${ }^{2}$, Hui Ye ${ }^{1}$ and Xinjian Lu ${ }^{1}$

\begin{abstract}
Background: The effects of restrictive fluid therapy combined with controlled hypotension in the elderly on systemic oxygen metabolism and renal function are clinical concerns. The aim of this study was to evaluate blood loss, oxygen metabolism, and renal function in different levels of controlled hypotension induced by intravenous nitroglycerin, in combination with limited infusion, in elderly patients undergoing posterior lumbar fusion.
\end{abstract}

Methods: A total of 40 patients, aged 60-75 with ASA grade II or III, who were planned for posterior lumbar fusion were randomly allocated into two groups: experimental group [target mean arterial pressure $65 \mathrm{mmHg}$ (MAP 65) or control group (MAP 75)]. Indicators for blood loss, hemodynamic, systemic oxygen metabolism, and renal function evaluation index were recorded before operation (T0), $1 \mathrm{~h}$ after induced hypotension (T1), $2 \mathrm{~h}$ after hypotension (T2), and in recovery (T3). We compared changes in these parameters between groups to evaluate the combined effects of controlled hypotension with restrictive infusion.

Results: $\mathrm{Cl}_{1} \mathrm{DO}_{2} l$, and $\mathrm{VO}_{2} l$ were lower in both groups at $\mathrm{T} 1-\mathrm{T} 3$ compared with $\mathrm{TO}(p<0.05)$. $\mathrm{DO}_{2} \mathrm{l}$ and $\mathrm{VO}_{2} l$ in the MAP 65 group were lower than the MAP 75 group after operation. In both groups, SCysC increased at T1, T2, and T3 $(p<0.05)$ compared with T0.

Conclusions: Restrictive transfusion and control MAP at $65 \mathrm{mmHg}$ can slightly change in renal function and reduce the risk of insufficient oxygen supply and importantly have no significant effect on blood loss and postoperative complications.

Trial registration: ChiCTR-INR-16008153. Registered on 25 March 2016.

Keywords: Controlled hypotension, Restrictive transfusion, Systemic oxygen metabolism, Renal function

\footnotetext{
* Correspondence: qxdong1969@163.com

'Department of Anesthesiology, Zhongda Hospital, Medical School, Southeast University, Nanjing, China

Full list of author information is available at the end of the article
}

(c) The Author(s). 2021 Open Access This article is licensed under a Creative Commons Attribution 4.0 International License, which permits use, sharing, adaptation, distribution and reproduction in any medium or format, as long as you give appropriate credit to the original author(s) and the source, provide a link to the Creative Commons licence, and indicate if changes were made. The images or other third party material in this article are included in the article's Creative Commons licence, unless indicated otherwise in a credit line to the material. If material is not included in the article's Creative Commons licence and your intended use is not permitted by statutory regulation or exceeds the permitted use, you will need to obtain permission directly from the copyright holder. To view a copy of this licence, visit http://creativecommons.org/licenses/by/4.0/ The Creative Commons Public Domain Dedication waiver (http://creativecommons.org/publicdomain/zero/1.0/) applies to the data made available in this article, unless otherwise stated in a credit line to the data. 


\section{Background}

Spondylosis, also known as degenerative disk diseases (DDD), refers to age-related degeneration of the spine motions segments, including vertebrae, facet joints, and intervertebral disks [1]. Clinical manifestation of lumbar spondylosis has been studied extensively, and the average incidence rate was reported at approximately 4.2 / 1000 person-years [2]. The condition affects people of wide-range ages with a peak incidence at approximately 40 [3], usually aggravated with increased age [4].

Posterior lumbar fusion is the main surgical procedure for treatment of spinal degenerative diseases [5]. Due to complex anatomy, the surgery is often complicated with trauma, long operation time, and significant bleeding [6]. Bleeding during operation not only affects the clarity of operation field which therefore may prolong operation, but also increases the risk of requirement of allogeneic blood transfusion, which could hinder postoperative rehabilitation [7]. Controlled hypotensive anesthesia is one of the most effective methods to reduce bleeding during surgery [8]. At present, the advantages of controlled hypotension in reducing intraoperative blood loss in spinal surgery have been widely recognized $[9,10]$. In major spinal surgeries, it has been proved to result in less blood loss and requirement of blood transfusion [11].

Controlled hypotension usually aimed at the reduction of the mean arterial pressure (MAP) by 30\% during anesthesia and surgery, while still providing adequate oxygen delivery to vital organs [12]. This is usually achieved by an absolute systolic pressure drop to about $80-90 \mathrm{mmHg}$, which translates to a MAP of $50-65$ $\mathrm{mmHg}$ [12]. Aging of the vascular system in elderly patients is often accompanied by increased vascular stiffness and decreased wall elasticity, which in turn leads to an increase in the proportion of simple systolic hypertension and microangiopathy, thereby affecting tissue perfusion [13]. Therefore, a low targeted MAP in controlled hypotension may be not suitable in these patients. An alternative is to combine controlled hypotension with higher targeted MAP with restrictive perioperative fluid supplement to ensure hemodynamic stability, improving perfusion and oxygenation of tissues and organs, as well as postoperative rehabilitation [14, 15]. It has been suggested that restrictive infusion in elderly patients reduced the incidence of postoperative anastomotic fistula and reduced the time of hospital stay [16].

However, restrictive transfusion infusion may lead to subclinical low circulatory blood volume, causing redistribution of systemic blood flow, leading to insufficient perfusion of the gastrointestinal tract, kidney, heart, and brain [17]. If controlled hypotension anesthesia is performed on the basis of restrictive transfusion, the additive effects on blood perfusion and systemic oxygen supply should be considered [8]. In addition, during controlled hypotension, renal blood flow decreases, and renal vasoconstriction, anti-diuretic hormone, and aldosterone secretion increase because of the drop in systemic perfusion pressure, which could lead to a decrease in glomerular filtration rate (GFR) [18].

Given these concerns, the effect of hypotension in combination with restrictive transfusion in elderly patients requires further investigation. Here, we explored the effects of controlled hypotension with two target MAP values $(65 \mathrm{mmHg}$ VS $75 \mathrm{mmHg}$ ) in combination with limited infusion, in elderly patients underwent lumbar fusion, in perspectives of intraoperative blood loss, systemic oxygen metabolism, and renal function.

\section{Methods}

\section{Patients}

In this exploratory interventional study, patients who were planned to undergo posterior lumbar fusion in Zhongda Hospital, Southeast University, during the period from March 2016 to January 2017, were screened. The inclusion criteria are (1) planned elective posterior multilevel (2-3) lumbar fusion under general anesthesia through tracheal intubation; (2) aged 60-75 years; (3) ASA grade II or III; and (4) estimated operative time > $120 \mathrm{~min}$. The exclusion criteria were (1) preoperative blood pressure systolic $\geq 160 \mathrm{mmHg}$ or diastolic $\geq 100$ $\mathrm{mmHg}$ or pulse pressure $\geq 60 \mathrm{mmHg}$; (2) comorbidities of severe cardiovascular disease, including cardiac function grade III or IV, severe aortic stenosis, aortic valve insufficiency, severe coronary heart disease, bradycardia, and atrioventricular block above degree I; (3) history of cerebral infarction, Alzheimer's disease, or cerebrovascular incident; (4) liver and/or kidney dysfunction; (5) severe anemia, shock, hypovolemia, or respiratory dysfunction; (6) previous history of phlebitis or thrombosis, closed-angle glaucoma; and (7) BMI $>25$ or $<18$. Patients with intraoperative blood loss $>1500 \mathrm{~mL}$ or operation time $>4 \mathrm{~h}$ would be further excluded from the analysis. This study was approved by the Ethics Committee of Zhongda Hospital, Southeast University (No. 2015ZDSYLL086.0). All patients gave written informed consent.

\section{Intervention}

Patients were allocated into trial group (MAP 65 group) or control group (MAP 75 group) with simple randomization method using random number table.

All operations were performed under general anesthesia, induced by intravenous infusion of $0.05 \mathrm{mg} / \mathrm{kg}$ midazolam (Jiangsu Enhua Pharmaceutical Co., Ltd., China; 20151002), $0.2-0.3 \mu \mathrm{g} / \mathrm{kg}$ sufentanil (Yichang human welfare pharmaceutical Co., Ltd., China; 1150720), $1.5 \mathrm{mg} / \mathrm{kg}$ propofol (Beijing Fesenius Kabi Medical Co., Ltd.; 10IC8536), and $0.6 \mathrm{mg} / \mathrm{kg}$ rocuronium (Oganon Corp. China; 640822). 
After the mask was pressurized with oxygen for $2 \mathrm{~min}$, endotracheal intubation was performed. Mechanical ventilation was set at tidal volume of $8 \mathrm{~mL} / \mathrm{kg}$ and ventilation frequency of 10-12 breaths per min. The breathing ratio was set to 1.0:2.0, with pure oxygen flow rate of $2.0 \mathrm{~L} / \mathrm{min}$ and maintained $\mathrm{PETCO}_{2}$ of $35 \sim 45 \mathrm{mmHg}$. After anesthesia induction, continuous infusion with propofol combined with sevoflurane (Marubeni pharmaceutical Co., Ltd.; 54171) and remifentanil was used to maintain analgesia, and intravenous injection of cis-atracurium (Jiangsu Hengrui Medical Co., Ltd., China; 15112317) was applied to maintain muscle relaxation.

\section{Controlled hypotension}

After the circulation stabilized, blood pressure control was initiated in both groups at time of incision, with the MAP 65 group aiming at maintaining MAP of $65 \mathrm{mmHg}$ and the MAP 75 group aiming at maintaining MAP of $75 \mathrm{mmHg}$. Nitroglycerin was intravenously administrated at initial rate of $0.5 \mathrm{~g} / \mathrm{kg} / \mathrm{min}$ using a programmed micropump. Blood pressure was continuously monitored; in every $3 \mathrm{~min}$ that the targeted MAP was not achieved, the infusion rate was increased by $0.5 \mu \mathrm{g} / \mathrm{kg} / \mathrm{min}$ until it was reached. Nitroglycerin infusion would be terminated immediately in case that MAP drop below the targeted goal, and in case when the MAP was still lower than targeted $3 \mathrm{~min}$ after termination of nitroglycerin infusion, a low dose of noradrenaline $(0.01 \sim 0.03 \mu \mathrm{g} / \mathrm{kg} / \mathrm{min})$ was applied to recover the target pressure. Blood pressure was controlled until the end of the decompression of the spinal canal.

During surgery, heart rate was controlled at 50-130 bpm, bispectral index (bis) was kept in anesthetic depth at 40-60, and body temperature was maintained at $36.3-37.2^{\circ} \mathrm{C}$. Importantly, if ischemic changes were observed on electrocardiogram, hypotension control was abandoned and this patient will be excluded from the study.

\section{Fluid management}

Both groups were fasted before anesthesia. Lactated Ringer's injection was administrated at $3 \mathrm{~mL} / \mathrm{kg} / \mathrm{h}$. Intraoperative blood loss was recovered by autologous blood transfusion and supplement of hydroxyethyl starch 130/ 0.4 in $0.9 \%$ sodium chloride at $1: 1$ ratio.

\section{Outcomes and data collection}

Parameters of perioperative bleeding, hemodynamic parameters, systemic oxygen metabolism, kidney functions, as well as procedure process and postoperative adverse reactions were recorded and compared between the groups.

Intraoperative dosage of crystal and colloid fluid, blood loss, volume, operation time of autologous blood transfusion, duration of hypotension, extubation time, exhaust time, and hospitalization time were recorded.

After patients entered the operation room, vital signs were monitored. Left radial artery catheters were inserted under local anesthesia. Flotrac sensors and Vigileo monitors were used to monitor MAP and cardiac index (CI). After endotracheal intubation, a catheter was inserted into the right internal jugular vein at a depth of $15 \mathrm{~cm}$ for both pump injection of nitroglycerin and monitoring of central venous pressure (CVP). Urinary catheterization was used to monitor urine volume.

The values of MAP, HR (heart rate), CI (cardiac index), and CVP (central venous pressure) before operation (T0), $1 \mathrm{~h}$ after hypotension (T1), $2 \mathrm{~h}$ after hypotension (T2), and in recovery stage (T3) were monitored and recorded.

Arterial and central venous blood samples were collected at the time points as mentioned above. Levels of hemoglobin $(\mathrm{Hb})$, lactate $(\mathrm{lac})$, arterial partial pressure of oxygen $\left(\mathrm{PaO}_{2}\right)$, central venous oxygen partial pressure $\left(\mathrm{PcVO}_{2}\right)$, arterial oxygen saturation $\left(\mathrm{SaO}_{2}\right)$, central venous oxygen saturation $\left(\mathrm{ScVO}_{2}\right)$, oxygen supply index $\left(\mathrm{DO}_{2} \mathrm{I}\right)$, oxygen consumption index $\left(\mathrm{VO}_{2} \mathrm{I}\right)$, and oxygen uptake rate $\left(\mathrm{ERO}_{2}\right)$ were detected using blood gas analyzer (NOVA Ultra; Nova Inc., USA).

Postoperative adverse reactions monitored included pulmonary complications (cough, sputum, shortness of breath, or dyspnea; pulmonary infection signs in chest $\mathrm{X}$-ray imaging; or atelectasis), gastrointestinal complications (nausea, vomiting, abdominal distension, or bowel sound disappearance), and wound infection (aggravated pain at wound position, local redness and tenderness, blood oozing and exudate on dressing, and unsatisfied wound healing).

Basic clinical data were collected from the patients' electronic medical records.

\section{Statistical analysis}

Quantitative data were expressed as means \pm SD and categorical data were expressed as frequency (percentage. The Shapiro-Smirnov test ( $d$ test) was used to test the normality of data distribution. The independent two samples Student $t$ test was used for the comparison between normally distributed quantitative data between the groups, and skewed distributed data were compared using two samples Mann-Whitney $U$ test. The $\chi^{2}$ test was used to compare categorical data. A $p$ value of $<$ 0.05 was considered statistically significant. All statistical analyses were performed using SPSS version 22.0 (IBM Corp., Armonk, NY, USA).

\section{Results}

Patients

A total of 144 elderly patients were scheduled to undergo selective posterior lumbar fusion during the 
study period, with 102 cases were excluded for different reasons. In addition, one patient in the MAP 65 group for whom the operation time was more than $4 \mathrm{~h}$ and one case in the MAP 75 group with intraoperative blood loss larger than $1500 \mathrm{ml}$ were excluded, resulting in $40 \mathrm{pa}$ tients, 20 in each group, in the final analysis (Fig. 1). Patients in the two groups showed no significant difference in age, sex, lumbar space, operation time, anesthetic time, or duration of hypotension (Table 1).

\section{Comparison of blood loss between the two groups}

As shown in Table 2, the amount of bleeding was not different between the two groups of patients $(p>0.05)$, and all patients did not receive allogeneic blood transfusion during surgery. There was neither significant difference in urine volume, colloidal fluid dosage, crystalloid dosage, total fluid volume, and auto-blood reclaiming between the two groups (Table 2).

\section{Comparison of hemodynamic indicators between the two} groups

As shown in Table 3 and Fig. 2, there was no significant difference in MAP between the two groups at T0 $(P>$ $0.05)$. Both groups were able to maintain targeted MAP at $\mathrm{T} 1$ and $\mathrm{T} 2$. In addition, MAP during recovery period (T3)

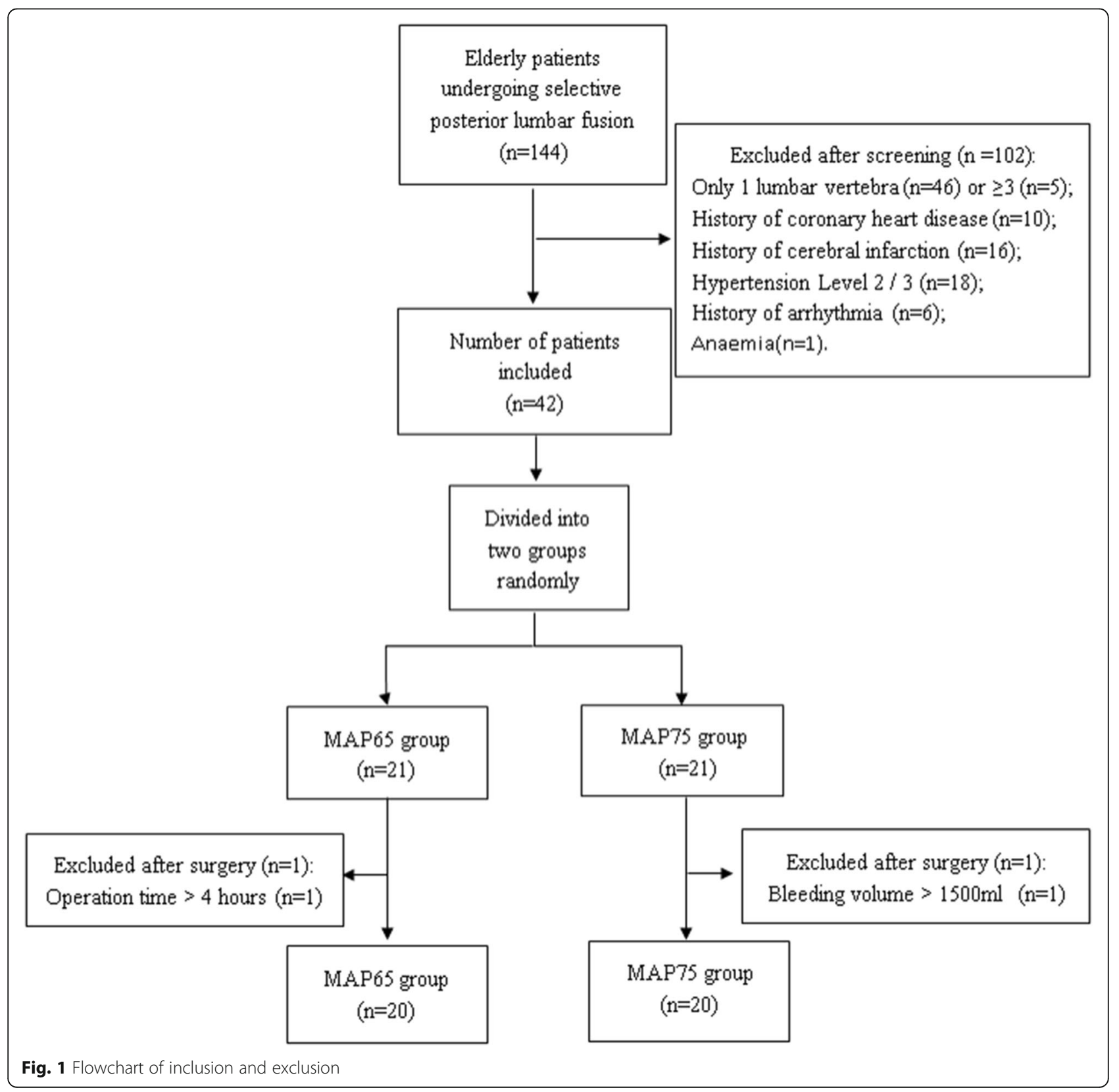


Table 1 Comparison of general data and surgical-related indexes between the two groups

\begin{tabular}{llll}
\hline & MAP $\mathbf{6 5}$ group & MAP 75 group & P value \\
& $\boldsymbol{n = 2 0}$ & $\boldsymbol{n}=\mathbf{2 0}$ & 0.9537 \\
\hline Age (years) & $67 \pm 5$ & $68 \pm 6$ & 0.3406 \\
Gender (M/F) & $7 / 13$ & $11 / 9$ & 0.2643 \\
BMI (kg/m2) & $21.9 \pm 1.9$ & $22.5 \pm 1.5$ & $>0.9999$ \\
ASA Grading composition (II/III) & $14 / 6$ & $15 / 5$ & $>0.9999$ \\
Lumbar vertebrae (2/3) & $14 / 6$ & $13 / 7$ & 0.9393 \\
operation time (min) & $196 \pm 32$ & $195 \pm 34$ & 0.6397 \\
Anesthesia duration (min) & $231 \pm 33$ & $226 \pm 34$ & 0.7850 \\
BP control time (min) & $129 \pm 11$ & $130 \pm 12$ &
\end{tabular}

was significantly decreased compared to T0 $(P<0.05)$ (Fig. 2a).

Before surgery (T0), there was no difference in HR between the two groups. In the MAP 65 group, significant decrease of HR compared to T0 was observed at T1 $(P<0.05)$, but not at T2 or T3 $(P>0.05)$. In the MAP 75 group, no significant changes in HR compared to that at T0 for all observed time points $(P>0.05)$. In addition, at all time points examined, HRs were not different between the two groups $(P>0.05)$ (Fig. 2b).

There was no significant difference in CIs between the two groups at T0 $(P>0.05)$. Compared to T0, CIs in both groups decreased significantly at T1-T3 $(P<0.05)$. Importantly, the CIs of the MAP 65 group were significantly lower than those of the MAP 75 group at T1-T3 $(P<0.05)$ (Fig. 2c).

Similarly, there was no significant difference in CVPs between the two groups at T0 $(P>0.05)$. In the MAP 65 group, significant decrease of CVP compared to T0 was observed at T2 $(P<0.05)$, but not at T1 and T3 $(P>0.05)$. In the MAP 75 group, CVPs at $\mathrm{T} 1$ and $\mathrm{T} 2$ were not significantly different from that of T0 $(P>0.05)$, but significantly lower CVP at T3 compared to T0 was observed $(\mathrm{P}<0.05)($ Fig. $2 \mathrm{~d})$.

\section{Comparison of systemic oxygen metabolism between the two groups}

There were no significant differences in $\mathrm{PaO}_{2}, \mathrm{SaO}_{2}$, $\mathrm{PcvO}_{2}$, and $\mathrm{ScvO}_{2}$ between the two groups at any time

Table 2 Comparison of intake and output between the two groups

\begin{tabular}{|c|c|c|c|}
\hline & $\begin{array}{l}\text { MAP } 65 \text { group } \\
n=20\end{array}$ & $\begin{array}{l}\text { MAP } 75 \text { group } \\
n=20\end{array}$ & $P$ value \\
\hline Amount of bleeding (ml) & $493 \pm 294$ & $564 \pm 311$ & 0.4627 \\
\hline Urine volume (ml) & $259 \pm 123$ & $210 \pm 98$ & 0.1716 \\
\hline Colloidal fluid usage (ml) & $215 \pm 121$ & $210 \pm 140$ & 0.9045 \\
\hline Crystal liquid usage (ml) & $1160 \pm 238$ & $1135 \pm 181$ & 0.7105 \\
\hline Total amount of liquid (ml) & $1392 \pm 263$ & $1350 \pm 221$ & 0.5877 \\
\hline Auto-blood reclaiming (ml) & $313 \pm 255$ & $388 \pm 56$ & 0.2067 \\
\hline
\end{tabular}

point $(P>0.05)$. In addition, no significant changes during and after procedure were observed in these parameters compared to T0 in both the two groups $(P>0.05)$ (Table 4).

The levels of $\mathrm{CaO}_{2}$ and $\mathrm{CcVO}_{2}$ were not different between the two groups at each time point $(P>0.05)$. In the MAP 65 group, compared with T0, the decrease in $\mathrm{CaO}_{2}$ at T2 and T3 was statistically significant $(P<0.05)$, and $\mathrm{CcVO}_{2}$ decreased significantly at time T2 $(P<0.05)$. In the MAP 75 group, the decrease in $\mathrm{CaO}_{2}$ at $\mathrm{T} 1-\mathrm{T} 3$ time was statistically significant $(P<0.05)$, and $\mathrm{CcVO}_{2}$ decreased significantly at the T1 and T2 $(P<0.05)$ compared to T0.

There was no significant difference in $[\mathrm{Hb}] \mathrm{s}$ between the two groups at all time points $(p>0.05)$. There was no significant difference in $[\mathrm{Hb}]$ between $\mathrm{T} 2$ and $\mathrm{T} 3$ and between $\mathrm{T} 1$ and $\mathrm{T} 0(p<0.05)$. At $\mathrm{T} 1-\mathrm{T} 3$ time points, $\mathrm{Hb}$ concentration decreased in the MAP 75 group $(p<$ $0.05)$. Interestingly, lactic acid concentration did not change over time in either the MAP 65 group or MAP 75 group.

At $\mathrm{T} 0$, the oxygen delivery index $\left(\mathrm{DO}_{2} \mathrm{I}\right)$ and oxygen consumption index $\left(\mathrm{VO}_{2} \mathrm{I}\right)$ was not different between the two groups. In both groups, $\mathrm{DO}_{2} \mathrm{I}$ and $\mathrm{VO}_{2} \mathrm{I}$ decreased in T1-T3 $(p<0.05)$ compared with T0. Meanwhile, the $\mathrm{DO}_{2} \mathrm{I}$ in the MAP 65 group at $\mathrm{T} 1-\mathrm{T} 3$ were lower than that in the MAP 75 group. Oxygen extraction rate $\left(\mathrm{ERO}_{2}\right)$ did not change in the process.

\section{Comparison of renal function parameters between the two groups}

There were no differences between the two groups in serum cystatin $\mathrm{C}(\mathrm{SCysC})$, creatinine $(\mathrm{Cr})$, and $\mathrm{BUN}$ at different time points. In the MAP 65 group, compared with T0, the level of SCysC decreased in T1-T3, Cr decreased in $\mathrm{T} 2$, but BUN had no changes. In the MAP 75 group, compared with $\mathrm{T} 0$, the level of $\mathrm{SCysC}$ increased at $\mathrm{T} 2$ and decreased at $\mathrm{T} 4$, the level of $\mathrm{Cr}$ increased at $\mathrm{T} 1$ and $\mathrm{T} 3$, and BUN increased at T1 and T4 (Table 5). 
Table 3 Comparison of hemodynamic change between the two groups

\begin{tabular}{|c|c|c|c|c|c|}
\hline & Group & TO & $\mathrm{T} 1$ & T2 & T3 \\
\hline \multirow[t]{2}{*}{ MAP (mmHg) } & MAP 65 group & $98 \pm 9$ & $65 \pm 3^{\#^{*}}$ & $65 \pm 2^{\#^{*}}$ & $85 \pm 8^{\#}$ \\
\hline & MAP 75 group & $100 \pm 8$ & $75 \pm 1^{\#}$ & $75 \pm 2^{\#}$ & $89 \pm 5^{\#}$ \\
\hline \multirow[t]{2}{*}{$\mathrm{HR}$ (/min) } & MAP 65 group & $74 \pm 10$ & $69 \pm 7^{\#}$ & $74 \pm 9$ & $72 \pm 10$ \\
\hline & MAP 75 group & $70 \pm 11$ & $66 \pm 5$ & $71 \pm 8$ & $72 \pm 7$ \\
\hline \multirow[t]{2}{*}{$\mathrm{Cl}\left(\mathrm{L} /\left(\min \mathrm{m}^{2}\right)\right)$} & MAP 65 group & $3.1 \pm 0.3$ & $2.1 \pm 0.4^{\#^{*}}$ & $2.0 \pm 0.3^{\#^{*}}$ & $2.0 \pm 0.5^{\#}$ \\
\hline & MAP 75 group & $3.2 \pm 0.2$ & $2.5 \pm 0.3^{\#}$ & $2.3 \pm 0.3^{\#}$ & $2.3 \pm 0.4^{\#}$ \\
\hline \multirow[t]{2}{*}{ CVP $\left(\mathrm{cmH}_{2} \mathrm{O}\right)$} & MAP 65 group & $9.9 \pm 3.4$ & $9.0 \pm 3.0$ & $8.4 \pm 3.2^{\#}$ & $8.9 \pm 3.2$ \\
\hline & MAP 75 group & $11.0 \pm 3.0$ & $11.0 \pm 3.0$ & $9.3 \pm 2.9$ & $8.7 \pm 3.1^{\#}$ \\
\hline
\end{tabular}

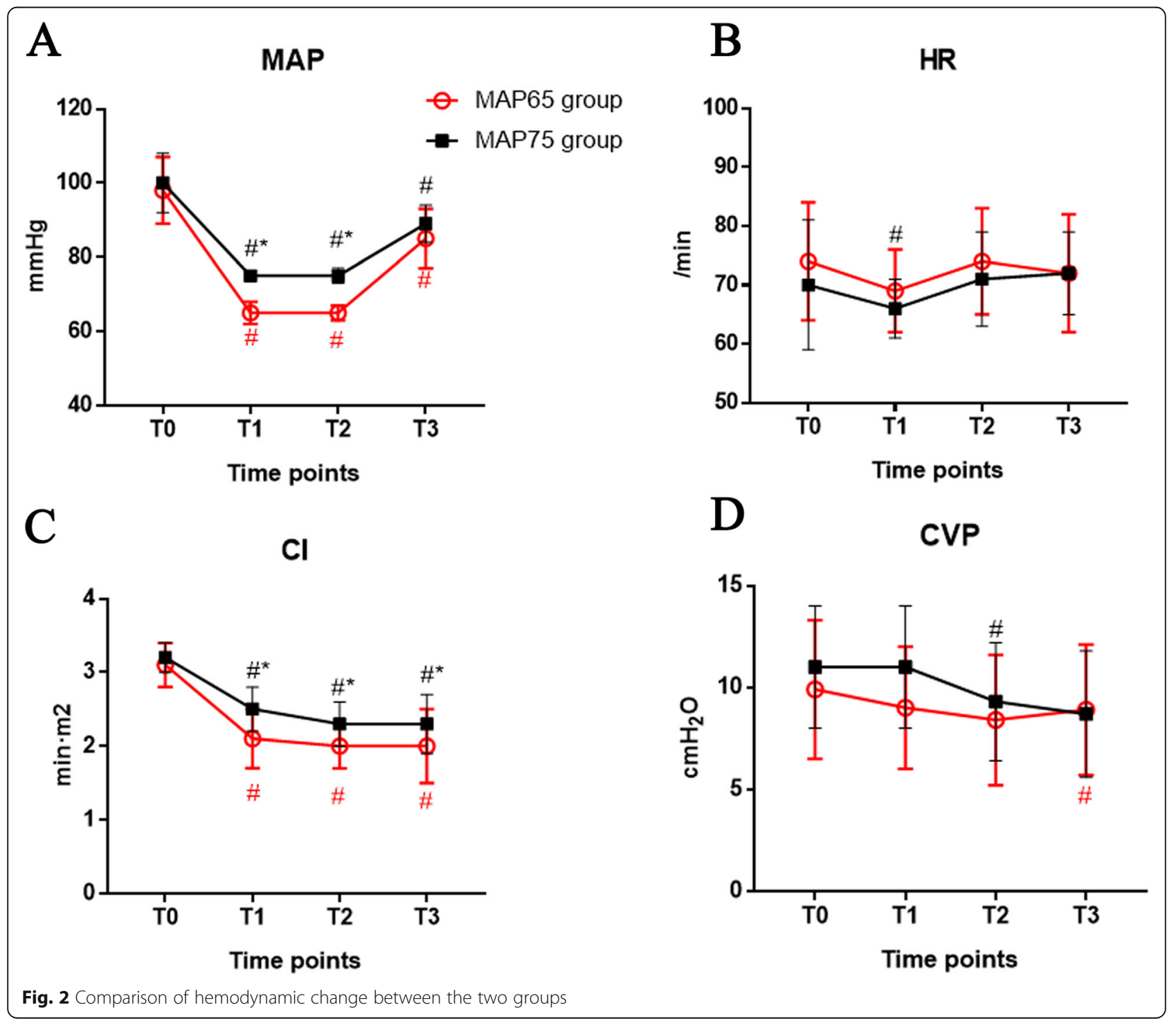


Table 4 Comparison of changes in systemic oxygen metabolism between the two groups $(\bar{x} \pm s, n=20)$

\begin{tabular}{|c|c|c|c|c|c|}
\hline & Group & T0 & $\mathrm{T} 1$ & $\mathrm{~T} 2$ & T3 \\
\hline \multirow[t]{2}{*}{$\mathrm{PaO}_{2}(\mathrm{mmHg})$} & MAP 65 group & $393 \pm 118$ & $391 \pm 118$ & $426 \pm 84$ & $430 \pm 105$ \\
\hline & MAP 75 group & $419 \pm 86$ & $431 \pm 87$ & $436 \pm 94$ & $418 \pm 98$ \\
\hline \multirow[t]{2}{*}{$\mathrm{SaO}_{2}(\%)$} & MAP 65 group & $99.6 \pm 0.5$ & $99.6 \pm 0.4$ & $99.6 \pm 0.3$ & $99.6 \pm 0.3$ \\
\hline & MAP 75 group & $99.4 \pm 1.2$ & $99.8 \pm 0.1$ & $99.8 \pm 0.1$ & $99.7 \pm 0.1$ \\
\hline \multirow[t]{2}{*}{$\mathrm{PcvO}_{2}(\mathrm{mmHg})$} & MAP 65 group & $55 \pm 9$ & $60 \pm 9$ & $59 \pm 10$ & $59 \pm 8$ \\
\hline & MAP 75 group & $55 \pm 5$ & $56 \pm 6$ & $57 \pm 8$ & $59 \pm 5$ \\
\hline \multirow[t]{2}{*}{$\mathrm{ScvO}_{2}(\%)$} & MAP 65 group & $85.3 \pm 5.1$ & $85.7 \pm 5.0$ & $84.7 \pm 5.2$ & $85.2 \pm 4.1$ \\
\hline & MAP 75 group & $85.7 \pm 3.3$ & $84.9 \pm 3.5$ & $84.8 \pm 4.9$ & $86.3 \pm 4.9$ \\
\hline \multirow[t]{2}{*}{$\mathrm{CaO}_{2}(\mathrm{ml} / \mathrm{L})$} & MAP 65 group & $163 \pm 8$ & $159 \pm 10$ & $152 \pm 14^{\#}$ & $154 \pm 14^{\#}$ \\
\hline & MAP 75 group & $166 \pm 10$ & $161 \pm 11^{\#}$ & $156 \pm 12^{\#}$ & $159 \pm 10^{\#}$ \\
\hline \multirow[t]{2}{*}{$\mathrm{CcvO}_{2}(\mathrm{ml} / \mathrm{L})$} & MAP 65 group & $137 \pm 10$ & $136 \pm 13$ & $129 \pm 18^{\#}$ & $131 \pm 14$ \\
\hline & MAP 75 group & $142 \pm 10$ & $136 \pm 12^{\#}$ & $131 \pm 13^{\#}$ & $136 \pm 10$ \\
\hline \multirow[t]{2}{*}{$\mathrm{Hb}(\mathrm{g} / \mathrm{L})$} & MAP 65 group & $121 \pm 6$ & $119 \pm 7$ & $113 \pm 10^{\#}$ & $115 \pm 10^{\#}$ \\
\hline & MAP 75 group & $123 \pm 8$ & $120 \pm 8^{\#}$ & $115 \pm 9^{\#}$ & $118 \pm 7^{\#}$ \\
\hline \multirow[t]{2}{*}{ Lactic acid (mmol/L) } & MAP 65 group & $1.2 \pm 0.5$ & $1.0 \pm 0.3$ & $1.0 \pm 0.4$ & $1.0 \pm 0.5$ \\
\hline & MAP 75 group & $1.0 \pm 0.5$ & $0.9 \pm 0.4$ & $0.9 \pm 0.4$ & $0.9 \pm 0.4$ \\
\hline \multirow[t]{2}{*}{$\mathrm{DO}_{2} \mathrm{l}\left(\mathrm{ml} / \mathrm{min} \mathrm{m}^{2}\right)$} & MAP 65 group & $509 \pm 57$ & $331 \pm 62^{\#^{*}}$ & $310 \pm 61^{\#^{*}}$ & $311 \pm 82^{\#^{*}}$ \\
\hline & MAP 75 group & $524 \pm 45$ & $405 \pm 47^{\#}$ & $349 \pm 56^{\#}$ & $366 \pm 61^{\#}$ \\
\hline \multirow[t]{2}{*}{$\mathrm{VO}_{2} \mathrm{I}\left(\mathrm{ml} / \mathrm{min} \mathrm{m}^{2}\right)$} & MAP 65 group & $78 \pm 18$ & $48 \pm 19^{\#^{*}}$ & $47 \pm 14^{\#}$ & $47 \pm 18^{\#}$ \\
\hline & MAP 75 group & $76 \pm 21$ & $63 \pm 15^{\#}$ & $55 \pm 19^{\#}$ & $52 \pm 21^{\#}$ \\
\hline \multirow[t]{2}{*}{$\mathrm{ERO}_{2}$} & MAP 65 group & $0.15 \pm 0.04$ & $0.15 \pm 0.05$ & $0.16 \pm 0.05$ & $0.15 \pm 0.04$ \\
\hline & MAP 75 group & $0.14 \pm 0.03$ & $0.16 \pm 0.03$ & $0.16 \pm 0.05$ & $0.14 \pm 0.05$ \\
\hline
\end{tabular}

Compared with T0, ${ }^{\#} P<0.05$; compared with MAP 75 group, ${ }^{*} P<0.05$

\section{Comparison of postoperative adverse reactions between the two groups}

There was no difference in extubation time or hospitalization time between the two groups. Importantly, postoperative fever, wound infection, pulmonary complications, and gastrointestinal complications were not significantly different between the MAP 65 group and MAP 75 group (Table 6).

\section{Discussion}

In this study, a pilot interventional study was performed to evaluate whether controlled hypotension in combination with restrictive transfusion can improve systemic oxygen metabolism, reduce intraoperative bleeding, and improve systemic hemodynamics. The results showed that controlled hypotension in combination with restrictive transfusion may improve renal function, reduce the risk of insufficient oxygen supply, and does not result in increased intraoperative blood loss or increased postoperative complications.

Previous study has shown that controlled hypotension reduces peripheral vascular resistance, resulting in reduced blood leakage from subcutaneous tissue, paravertebral muscles, and epidural veins [19]. Wonjung et al. found that the blood loss of the elderly (aged 60-70) patients who underwent spinal surgery without controlled

Table 5 Comparison of renal function indexes between two groups at different time points $(\bar{x} \pm s, n=20)$

\begin{tabular}{|c|c|c|c|c|c|c|}
\hline & Group & T0 & $\mathrm{T} 1$ & T2 & T3 & T4 \\
\hline \multirow[t]{2}{*}{ SCysC (mg/L) } & MAP 65 group & $0.74 \pm 0.13$ & $0.81 \pm 0.13^{\#}$ & $0.87 \pm 0.14^{\#}$ & $0.79 \pm 0.14^{\#}$ & $0.71 \pm 0.13$ \\
\hline & MAP 75 group & $0.76 \pm 0.16$ & $0.80 \pm 0.17$ & $0.84 \pm 0.18^{\#}$ & $0.84 \pm 0.20$ & $0.68 \pm 0.13^{\#}$ \\
\hline \multirow[t]{2}{*}{$\mathrm{Cr}(\mu \mathrm{mol} / \mathrm{L})$} & MAP 65 group & $76 \pm 15$ & $78 \pm 14$ & $80 \pm 13^{\#}$ & $74 \pm 14$ & $77 \pm 14$ \\
\hline & MAP 75 group & $72 \pm 13$ & $76 \pm 16^{\#}$ & $74 \pm 21$ & $79 \pm 15^{\#}$ & $72 \pm 14$ \\
\hline \multirow[t]{2}{*}{ BUN (mmol/L) } & MAP 65 group & $4.8 \pm 0.9$ & $4.9 \pm 1.0$ & $5.2 \pm 1.5$ & $5.2 \pm 1.3$ & $4.5 \pm 0.8$ \\
\hline & MAP 75 group & $4.6 \pm 1.0$ & $4.7 \pm 1.0^{\#}$ & $4.8 \pm 1.3$ & $4.8 \pm 1.0$ & $4.1 \pm 1.3^{\#}$ \\
\hline
\end{tabular}

Compared with T0, ${ }^{\#} P<0.05$; compared with MAP 75 group, ${ }^{*} P<0.05$ 
Table 6 Comparison of renal function indexes between two groups at different time points $(\bar{x} \pm s, n=20)$

\begin{tabular}{llll}
\hline & $\begin{array}{l}\text { MAP 65 group } \\
(\boldsymbol{n = 2 0 )}\end{array}$ & $\begin{array}{l}\text { MAP 75 group } \\
(\boldsymbol{n}=\mathbf{2 0})\end{array}$ & $\begin{array}{c}\boldsymbol{P} \text { value } \\
\text { Extubation time (min) }\end{array}$ \\
Hospitalization time (days) & $19 \pm 9$ & $23 \pm 13$ & 0.2650 \\
Postoperative fever (\%) & $13 \pm 3$ & $14 \pm 3$ & 0.2985 \\
Wound infection (\%) & 20 & 30 & 0.7164 \\
Pulmonary complications (\%) & 0 & 0 & $>0.9999$ \\
Gastrointestinal complications (\%) & 0 & 0 & $>0.9999$ \\
\hline
\end{tabular}

hypotension was $765 \pm 339 \mathrm{~mL}$, while turned to $445.0 \pm$ $226.5 \mathrm{~mL}$ with controlled hypotension [6]. In this study, the amount of intraoperative blood loss was $493 \pm 294$ $\mathrm{mL}$ and $564 \pm 311 \mathrm{~mL}$ in the two groups. Although blood loss volumes in different studies may not be comparable, the results still may hint that induced hypotension in this study could have resulted in less blood loss. There was little need for transfusion of allogeneic blood. Although no statistical significant difference was detected between the two groups, which may be due to the limited sample size, the results did indicate an even lower amount of blood loss when MAP was controlled at 65 $\mathrm{mmHg}$ with restrictive infusion, compared to targeted MAP of $75 \mathrm{mmHg}$.

Controlled hypotension, as well as surgical posture itself, may have a significant effect on CI. It has been suggested that the protruding position pad caused a significant decrease in CI, but no significant change in other hemodynamic indexes [20]. In this study, CI in both groups decreased significantly compared with t0 at T1-T3 time point, which indicates that the decrease in blood pressure will further reduce CI, in addition to the postural change. The results of CVP changes were not expected, especially when MAP was controlled at 75 $\mathrm{mmHg}$. We suspect that the prone position affected the vena cava reflux, thereby increasing CVP. Furthermore, even under the condition of controlled hypotension and restrictive infusion, the change in CVP was not significant and whether it is a repeatable phenomenon requires further study.

The purpose of monitoring hemodynamic indexes during operation is to maintain good perfusion of tissues and organs to maintain normal metabolism and prevent hypoxia and apoptosis of tissue cells from causing dysfunction of the organism. The most basic clinical monitoring indexes such as $\mathrm{SpO}_{2}$ and $\mathrm{PetCO}_{2}$ cannot fully describe the state of oxygen metabolism. At present, the main indexes of oxygen metabolism are oxygen supply index $\left(\mathrm{DO}_{2} \mathrm{I}\right)$, oxygen consumption index $\left(\mathrm{VO}_{2} \mathrm{I}\right)$, oxygen uptake rate $\left(\mathrm{ERO}_{2}\right)$, and lactate. In this experiment, the two groups were both on pure oxygen positive pressure ventilation, and there was no significant difference in $\mathrm{Hb}, \mathrm{PaO}_{2}, \mathrm{SaO}_{2}$, and $\mathrm{CaO}_{2}$; therefore, the decrease in
$\mathrm{DO}_{2} \mathrm{I}$ might be mainly due to the decrease in CI. In addition, the decreasing trends of $\mathrm{CaO}_{2}$ and $[\mathrm{Hb}]$ were consistent, so the changes of $\mathrm{DO}_{2} \mathrm{I}$ were mainly affected by $[\mathrm{Hb}]$ and $\mathrm{CI}$ over time. All these results suggested that the combination of controlled hypotension and restrictive transfusion could significantly improve oxygen supply.

In this study, renal function indicators including urea nitrogen (BUN), creatinine $(\mathrm{Cr})$, and serum cystatin (SCysC) were dynamically monitored. Compared with T0, SCysC in the MAP 65 group increased significantly after hypotension and recovered to the initial level 1 day after operation, whereas $\mathrm{Cr}$ only increased significantly at T2. SCysC in the MAP 75 group only increased significantly at $\mathrm{T} 2, \mathrm{Cr}$ rises at $\mathrm{T} 1$ and $\mathrm{T} 3$, and BUN increases at $\mathrm{T} 1$ and decreases at $\mathrm{T} 4$. These results indicated that in elderly patients, reducing MAP to 65 $\mathrm{mmHg}$ while limiting fluid intake may result in a slight improvement of renal function. Whether GFR can be reduced effectively or not, as well as the obvious improvement of renal function, remains to be further studied.

Our study has potential limitations. First, in order to strictly adhere to inclusion and exclusion criteria, a limited number of cases were selected, resulting in a smaller sample size. Second, chronic diseases which are common in elderly may affect the changes in the monitoring parameters while due to limited sample size and data, the influences were not explored. Further research needs to be explored in this regard.

\section{Conclusions}

In elderly patients subjected to posterior lumbar fusion, controlled hypotension targeting a MAP of $75 \mathrm{mmHg}$ in combination with restrictive transfusion, compared with controlled hypotension with $65 \mathrm{mmHg}$, met the requirements for reducing intraoperative blood loss and allogeneic blood transfusion, with little effects on renal function and oxygen supply, whereas control hypotension with targeted MAP of $65 \mathrm{mmHg}$ may significantly reduce the risk of $\mathrm{CI}$ and oxygen supply.

\section{Abbreviations}

DDD: Degenerative disk diseases; MAP: Mean arterial pressure; bis: Bispectral index; Cl: Cardiac index; CVP: Central venous pressure; Hb: Hemoglobin; 
lac: Lactate; $\mathrm{PaO}_{2}$ : Arterial partial pressure of oxygen; $\mathrm{PcVO}_{2}$ : Central venous oxygen partial pressure; $\mathrm{SaO}_{2}$ : Arterial oxygen saturation; $\mathrm{ScVO}_{2}$ : Central venous oxygen saturation; $\mathrm{DO}_{2}$ l: Oxygen supply index; $\mathrm{VO}_{2} l$ : Oxygen consumption index; $\mathrm{ERO}_{2}$ : Oxygen uptake rate; $\mathrm{DO}_{2}$ : Oxygen delivery index; $\mathrm{ERO}_{2}$ : Oxygen extraction rate; SCysC: Serum cystatin $\mathrm{C}_{;} \mathrm{Cr}$ : Creatinine; BUN: Urea nitrogen; GFR: Glomerular filtration rate

\section{Authors' contributions}

QXD wrote and revised the manuscript. TZY and TWH performed the statistical analyses. YH and LXJ collected clinical information. QXD designed the study. All authors have read and approved the final manuscript.

\section{Funding}

This trial was conducted with no external funding and internal funding

\section{Availability of data and materials}

All data generated or analyzed during this study are included in this published article.

\section{Ethics approval and consent to participate}

This experiment was approved by the Ethics Committee of Zhongda Hospital, Southeast University (No. 2015ZDSYLL086.0). All patients gave written informed consent.

\section{Consent for publication}

Not applicable.

\section{Competing interests}

The authors declare that they have no competing interests.

\section{Author details}

'Department of Anesthesiology, Zhongda Hospital, Medical School, Southeast University, Nanjing, China. ${ }^{2}$ Department of General Surgery, Zhongda Hospital of Southeast University, No. 87 Dingjiaqiao, Nanjing 210009, China.

Received: 18 December 2018 Accepted: 31 December 2020

Published online: 28 January 2021

\section{References}

1. Noshchenko A, Hoffecker L, Lindley EM, Burger EL, Cain CM, Patel W. Longterm treatment effects of lumbar arthrodeses in degenerative disk disease: a systematic review with meta-analysis. J Spinal Disord Tech. 2015;28(9):E493521. https://doi.org/10.1097/bsd.0000000000000124.

2. Schoenfeld AJ, Nelson JH, Burks R, Belmont PJ Jr. Incidence and risk factors for lumbar degenerative disc disease in the United States military 19992008. Mil Med. 2011;176(11):1320-4

3. Suthar P, Patel R, Mehta C, Patel N. MRI evaluation of lumbar disc degenerative disease. J Clin Diagn Res. 2015;9(4):Tc04-9. https://doi.org/10 7860/jcdr/2015/11927.5761

4. Orzaez D, Medina A, Torre S, Fernandez-Moreno JP, Rambla JL, FernandezDel-Carmen A, et al. A visual reporter system for virus-induced gene silencing in tomato fruit based on anthocyanin accumulation. Plant Physiol. 2009;150(3):1122-34. https://doi.org/10.1104/pp.109.139006

5. Park SY, An HS, Lee SH, Suh SW, Kim JL, Yoon SJ. A prospective randomized comparative study of postoperative pain control using an epidural catheter in patients undergoing posterior lumbar interbody fusion. Eur Spine J. 2016; 25(5):1601-7. https://doi.org/10.1007/s00586-016-4385-8.

6. Hwang W, Kim E. The effect of milrinone on induced hypotension in elderly patients during spinal surgery: a randomized controlled trial. Spine J. 2014; 14(8):1532-7. https://doi.org/10.1016/j.spinee.2013.09.028.

7. Kako H, Gable A, Martin D, Beebe A, Thung A, Samora W, et al. A prospective, open-label trial of clevidipine for controlled hypotension during posterior spinal fusion. J Pediatr Pharmacol Ther. 2015;20(1):54-60. https://doi.org/10.5863/1551-6776-20.1.54

8. Ghodraty MR, Homaee MM, Farazmehr K, Nikzad-Jamnani AR, SoleymaniDodaran M, Pournajafian AR, et al. Comparative induction of controlled circulation by magnesium and remifentanil in spine surgery. World $J$ Orthop. 2014;5(1):51-6. https://doi.org/10.5312/wjo.v5.11.51.
9. Gerson Jl, Allen FB, Seltzer JL, Parker FB Jr, Markowitz AH. Arterial and venous dilation by nitroprusside and nitroglycerin--is there a difference? Anesth Analg. 1982;61(3):256-60

10. Van Hemelrijck J, Waets P, Van Aken H, Lacroix H, Nevelsteen A, Suy R. Blood pressure management during aortic surgery: urapidil compared to isosorbide dinitrate. J Cardiothorac Vasc Anesth. 1993;7(3):273-8.

11. Malcolm-Smith NA, McMaster MJ. The use of induced hypotension to control bleeding during posterior fusion for scoliosis. J Bone Joint Surg Br Vol. 1983;65(3):255-8.

12. Rodrigo C. Induced hypotension during anesthesia with special reference to orthognathic surgery. Anesth Prog. 1995:42(2):41-58.

13. Steppan J, Barodka V, Berkowitz DE, Nyhan D. Vascular stiffness and increased pulse pressure in the aging cardiovascular system. Cardiol Res Pract. 2011;2011:263585. https://doi.org/10.4061/2011/263585.

14. Vallet B, Futier E. Perioperative oxygen therapy and oxygen utilization. Curr Opin Crit Care. 2010;16(4):359-64. https://doi.org/10.1097/MCC. Ob013e32833bfa3b.

15. Esteve-Perez N, Ferrer-Robles A, Gomez-Romero G, Fabian-Gonzalez D, VerdRodriguez M, Mora-Fernandez LC, et al. Goal-directed therapy in cytoreductive surgery with hyperthermic intraperitoneal chemotherapy: a prospective observational study. Clin Transl Oncol. 2018. https://doi.org/10 1007/s12094-018-1944-y.

16. Piegeler T, Dreessen P, Graber SM, Haile SR, Schmid DM, Beck-Schimmer B. Impact of intraoperative fluid administration on outcome in patients undergoing robotic-assisted laparoscopic prostatectomy-a retrospective analysis. BMC Anesthesiol. 2014:14:61, https:/doi.org/10.1186/1471-2253-14-61.

17. Gonzalez-Fajardo JA, Mengibar L, Brizuela JA, Castrodeza J, Vaquero-Puerta C. Effect of postoperative restrictive fluid therapy in the recovery of patients with abdominal vascular surgery. Eur J Vasc Endovasc Surg. 2009;37(5):53843. https://doi.org/10.1016/j.ejvs.2009.01.010.

18. Gladden LB. A lactatic perspective on metabolism. Med Sci Sports Exerc. 2008;40(3):477-85. https://doi.org/10.1249/MSS.0b013e31815fa580

19. Relton JE, Hall JE. An operation frame for spinal fusion. A new apparatus designed to reduce haemorrhage during operation. J Bone Joint Surg Br Vol. 1967:49(2):327-32

20. Yokoyama M, Ueda W, Hirakawa M, Yamamoto H. Hemodynamic effect of the prone position during anesthesia. Acta Anaesthesiol Scand. 1991;35(8): $741-4$.

\section{Publisher's Note}

Springer Nature remains neutral with regard to jurisdictional claims in published maps and institutional affiliations.

Ready to submit your research? Choose BMC and benefit from:

- fast, convenient online submission

- thorough peer review by experienced researchers in your field

- rapid publication on acceptance

- support for research data, including large and complex data types

- gold Open Access which fosters wider collaboration and increased citations

- maximum visibility for your research: over $100 \mathrm{M}$ website views per year

At BMC, research is always in progress.

Learn more biomedcentral.com/submission 